\title{
Evaluation of a Hospitalist-Run Acute Care for the Elderly Service
}

\author{
Heidi L. Wald, MD, MSPH${ }^{1,2}$, Jeffrey J. Glasheen, $\mathrm{MD}^{2}$, Jeannette Guerrasio, MD², Jean M. Youngwerth, $\mathrm{MD}^{2}$
} Ethan Ulysses Cumbler, MD²

${ }^{1}$ Division of Health Care Policy Research, University of Colorado Denver School of Medicine, Aurora, Colorado; ${ }^{2}$ Division of General Internal Medicine, Section of Hospital Medicine, University of Colorado Denver School of Medicine, Aurora, Colorado

BACKGROUND: Comprehensive care for frail older inpatients may improve selected outcomes and reduce harm.

OBJECTIVE: To evaluate a Hospitalist-run Acute Care for the Elderly (Hospitalist-ACE) service.

DESIGN: Quasi-randomized, controlled trial.

SETTING: Urban academic medical center.

PATIENTS: Medical inpatients age $\geq 70$ years.

INTERVENTION: Hospitalist-ACE service components: 1) selected hospitalist attendings; 2) daily interdisciplinary rounds; 3) standardized geriatric assessment; 4) clinical focus on mitigating harm and discharge planning; 5) novel inpatient geriatrics curriculum.

MEASURES: The primary outcome was recognition of abnormal functional status by the primary medical team. Secondary outcomes included: recognition of abnormal cognitive status and delirium by the primary medical team; use of physical restraints and sleep aids; documentation of code status; hospital charges, length of stay, readmission rates, discharge location, and falls.

RESULTS: One hundred twenty-two Hospitalist-ACE patients were compared to 95 usual care patients. Hospitalist-ACE patients had significantly greater recognition of abnormal functional status (65\% vs $32 \%, P<0.0001)$, and abnormal cognitive status (57\% vs $36 \%, P=0.02)$, and greater use of "Do Not Attempt Resuscitation" orders (39\% vs $26 \%, P=$ 0.04). There were no differences in use of physical restraints, or sleep aids, falls, or discharge location. Hospitalist-ACE patients and usual care patients had similar mean lengths of stay in days $(3.4 \pm 2.7$ vs $3.1 \pm 2.7, P=0.52)$, mean charges $(\$ 24,617 \pm \$ 15,828$ vs $\$ 21,488 \pm \$ 13,407, P=0.12)$, and $30-$ day readmission rates ( $12 \%$ vs $10 \%, P=0.50)$.

CONCLUSIONS: A Hospitalist-ACE service may improve care processes without significantly increasing resource consumption. No impact on key clinical outcomes was observed. Journal of Hospital Medicine 2011;6:313-321. (C) 2011 Society of Hospital Medicine
For the frail older patient, hospitalization marks a period of high risk of poor outcomes and adverse events including functional decline, delirium, pressure ulcers, adverse drug events, nosocomial infections, and falls. ${ }^{1,2}$ Physician recognition of elderly patients at risk for adverse outcomes is poor, making it difficult to intervene to prevent them. ${ }^{3,4}$ Among frail, elderly inpatients at an urban academic medical center, doctors documented cognitive assessments in only $5 \%$ of patients. Functional assessments are appropriately documented in $40 \%-80 \%$ of inpatients. ${ }^{3,5}$

The Acute Care for Elders (ACE) unit is one of several models of comprehensive inpatient geriatric care that have been developed by geriatrician researchers to address the adverse events and functional decline that often accompany hospitalization. ${ }^{6}$ The ACE unit

*Address for correspondence and reprint requests: Heidi L. Wald, MD, MSPH, Division of Health Care Policy Research, 13611 E. Colfax Avenue, Suite 100, Aurora, CO 80045; Tel.: 303-725-8725; E-mail: heidi.wald@ucdenver.edu

Additional Supporting Information may be found in the online version of this article.

Received: April 14, 2010; Revised: January 12, 2011; Accepted: January 16, 2011

2011 Society of Hospital Medicine DOI 10.1002/jhm.906

Published online in Wiley Online Library (Wileyonlinelibrary.com). model generally incorporates: 1) a modified hospital environment, 2) early assessment and intensive management to minimize the adverse effects of hospital care, 3 ) early discharge planning, 4) patient centered care protocols, and 5) a consistent nursing staff. ${ }^{7}$ Two randomized, controlled trials have shown the ACE unit model to be successful in reducing functional decline among frail older inpatients during and after hospitalization. ${ }^{7,8}$ While meta-analyses data also suggests the ACE unit model reduces functional decline and future institutionalization, significant impact on other outcomes is not proven. ${ }^{9,10}$

Several barriers have prevented the successful dissemination of the ACE unit model. The chief limitations are the upfront resources required to create and maintain a modified, dedicated unit, as well as the lack of a geriatrics trained workforce. ${ }^{7,11-13}$ The rapid growth of hospital medicine presents opportunities for innovation in the care of older patients. Still, a 2006 census demonstrated that few hospitalist groups had identified geriatric care as a priority. ${ }^{14}$

In response to these challenges, the University of Colorado Hospital Medicine Group created a hospitalist-run inpatient medical service designed for the care of the frail older patient. This Hospitalist-Acute Care for the Elderly (Hospitalist-ACE) unit is a hybrid 
of a general medical service and an inpatient geriatrics unit. $^{7}$ The goals of the Hospitalist-ACE service are to provide high quality care tailored to older inpatients, thus minimizing the risks of functional decline and adverse events associate with hospitalization, and to provide a clinical geriatrics teaching experience for Hospitalist Training Track Residents within the Internal Medicine Residency Training Program and medical students at the University of Colorado Denver School of Medicine. The Hospitalist-ACE unit is staffed with a core group of hospitalist attendings who have, at a minimum, attended an intensive minicourse in inpatient geriatrics. The service employs interdisciplinary rounds; a brief, standardized geriatric assessment including screens of function, cognition, and mood; a clinical focus on mitigating the hazards of hospitalization, early discharge planning; and a novel geriatric educational curriculum for medicine residents and medical students.

This article will: 1) describe the creation of the Hospitalist-ACE service at the University of Colorado Hospital; and 2) summarize the evaluation of the HospitalistACE service in a quasi-randomized, controlled manner during its first year. We hypothesized that, when compared to patients receiving usual care, patients cared for on the Hospitalist-ACE service would have increased recognition of abnormal functional status; recognition of abnormal cognitive status and delirium; equivalent lengths of stay and hospital charges; and decreased falls, 30-day readmissions, and restraint use.

\section{METHODS \\ Design}

We performed a quasi-randomized, controlled study of the Hospitalist-ACE service.

\section{Setting}

The study setting was the inpatient general medical services of the Anschutz Inpatient Pavilion (AIP) of the University of Colorado Hospital (UCH). The AIP is a 425-bed tertiary care hospital that is the major teaching affiliate of the University of Colorado School of Medicine and a regional referral center. The control services, hereafter referred to as usual care, were comprised of the four inpatient general medicine teaching services that take admissions on a four-day rotation (in general, two were staffed by outpatient general internists and medical subspecialists, and two were staffed by academic hospitalists). The Hospitalist-ACE service was a novel hospitalist teaching service that began in July 2007. Hospitalist-ACE patients were admitted to a single 12-bed medical unit (12 West) when beds were available; 12 West is similar to the other medical/surgical units at $\mathrm{UCH}$ and did not have any modifications to the rooms, equipment, or common areas for the intervention. The nursing staff on this unit had no formal geriatric nursing training. The Hospitalist-ACE team admitted patients daily (between 7 AM and 3 PM Monday-Friday; between 7 $\mathrm{AM}$ and 12 noon Saturday and Sunday). Patients assigned to the Hospitalist-ACE service after hours were admitted by the internal medicine resident on call for the usual care services and handed off to the Hospitalist-ACE team at $7 \mathrm{AM}$ the next morning.

\section{Study Subjects}

Eligible subjects were inpatients age $\geq 70$ years admitted to the usual care or Hospitalist-ACE services at the AIP from November 2, 2007 to April 15, 2008. All patients age $\geq 70$ years were randomized to the Hospitalist-ACE service or usual care on a general internal medicine service by the last digit of the medical record number (odd numbers admitted to the Hospitalist-ACE service and even numbers admitted to usual care). Patients followed by the Hospitalist-ACE service but not admitted to 12 West were included in the study. To isolate the impact of the intervention, patients admitted to a medicine subspecialty service (such as cardiology, pulmonary, or oncology), or transferred to or from the Hospitalist-ACE or control services to another service (eg, intensive care unit [ICU] or orthopedic surgery service) were excluded from the study.

\section{Intervention}

The Hospitalist-ACE unit implemented an interdisciplinary team approach to identify and address geriatric syndromes in patients aged 70 and over. The Hospitalist-ACE model of care consisted of clinical care provided by a hospitalist attending with additional training in geriatric medicine, administration of standardized geriatric screens assessing function, cognition, and mood, 15 minute daily (Monday-Friday) interdisciplinary rounds focusing on recognition and management of geriatric syndromes and early discharge planning, and a standardized educational curriculum for medical residents and medical students addressing hazards of hospitalization.

The Hospitalist-ACE service was a unique rotation within the Hospitalist Training Track of the Internal Medicine Residency that was developed with the support of the University of Colorado Hospital and the Internal Medicine Residency Training Program, and input from the Geriatrics Division at the University of Colorado Denver. The director received additional training from the Donald W. Reynolds FoundationUCLA Faculty Development to Advance Geriatric Education Mini-Fellowship for hospitalist faculty. The mission of the service was to "excel at educating the next generation of hospitalists while providing a model for excellence of care for hospitalized elderly patients." Important stakeholders were identified, and a leadership team-including representatives from nursing, physical and occupational therapy, pharmacy, social work, case management, and later, volunteer services-created the model daily interdisciplinary 
rounds. As "geographic concentration" was essential for the viability of interdisciplinary rounds, one unit (12 West) within the hospital was designated as the preferred location for patients admitted to the Hospitalist-ACE service.

The Hospitalist-ACE unit team consisted of one attending hospitalist, one resident, one intern, and medical students. The attending was one of five hospitalists, with additional training in geriatric medicine, who rotated attending responsibilities on the service. One of the hospitalists was board certified in geriatric medicine. Each of the other four hospitalists attended the Reynolds Foundation-UCLA mini-fellowship in geriatric medicine. Hospitalist-ACE attendings rotated on a variety of other hospitalist services throughout the academic year, including the usual care services.

The brief standardized geriatric assessment consisted of six validated instruments, and was completed by house staff or medical students on admission, following instruction by the attending physician. The complete assessment tool is shown in Figure 1. The cognitive items included the Mini-Cog, ${ }^{15}$ a two-item depression screen, ${ }^{16}$ and the Confusion Assessment Method. ${ }^{17}$ The functional items included the Vulnerable Elders Survey (VES-13), ${ }^{18}$ the Timed Get Up and Go test, ${ }^{19}$ and a two-question falls screen. ${ }^{20}$ The elements of the assessment tool were selected by the Hospitalist-ACE attendings for brevity and the potential to inform clinical management. To standardize the clinical and educational approach, the Hospitalist-ACE attendings regularly discussed appropriate orders recommended in response to each positive screen, but no templated order sets were used during the study period.

Interdisciplinary rounds were attended by Hospitalist-ACE physicians, nurses, case managers, social workers, physical or occupational therapists, pharmacists, and volunteers. Rounds were led by the attending or medical resident.

The educational curriculum encompassed 13 modules created by the attending faculty that cover delirium, falls, dementia, pressure ulcers, physiology of aging, movement disorders, medication safety, end of life care, advance directives, care transitions, financing of health care for the elderly, and ethical conundrums in the care of the elderly. A full table of contents appears in online Appendix 1. Additionally, portions of the curriculum have been published online. ${ }^{21,22}$ Topic selection was guided by the Accreditation Council for Graduate Medical Education (ACGME) core geriatrics topics determined most relevant for the inpatient setting. Formal instruction of 30-45 minutes duration occurred three to four days a week and was presented in addition to routine internal medicine educational conferences. Attendings coordinated teaching to ensure that each trainee was exposed to all of the content during the course of their four-week rotation.

In contrast to the Hospitalist-ACE service, usual care on the control general medical services consisted of either a hospitalist, a general internist, or an internal medicine subspecialist attending physician, with one medical resident, one intern, and medical students admitting every fourth day. The general medical teams attended daily discharge planning rounds with a discharge planner and social worker focused exclusively on discharge planning. The content of teaching rounds on the general medical services was largely left to the discretion of the attending physician.

This program evaluation of the Hospitalist-ACE service was granted a waiver of consent and Health Insurance Portability and Accountability Act (HIPAA) by the Colorado Multiple Institutional Review Board.

\section{Measures}

\section{Primary Outcome}

The primary outcome for the study was the recognition of abnormal functional status by the primary team. Recognition of abnormal functional status was determined from chart review and consisted of both the physician's detection of abnormal functional status and evidence of a corresponding treatment plan identified in the notes or orders of a physician member of the primary team (Table 1$)$.

\section{Secondary Outcomes}

Recognition of abnormal cognitive status was determined from chart review and consisted of both the physician's detection of dementia, depression, or delirium, and evidence of a corresponding treatment plan for any of the documented conditions identified in the notes or orders of a physician member of the primary team (Table 1). Additionally, we measured recognition and treatment of delirium alone.

Falls were determined from mandatory event reporting collected by the hospital on the University Hospitals Consortium Patient Safety Net web-based reporting system and based on clinical assessment as reported by the nursing staff. The reports are validated by the appropriate clinical managers within 45 days of the event according to standard procedure.

Physical restraint use (type of restraint and duration) was determined from query of mandatory clinical documentation in the electronic medical record. Use of sleep aids was determined from review of the physician's order sheets in the medical record. The chart review captured any of 39 commonly prescribed hypnotic medications ordered at hour of sleep or for insomnia. The sleep medication list was compiled with the assistance of a pharmacist for an earlier chart review and included non-benzodiazepine hypnotics, benzodiazepines, antidepressants, antihistamines, and antipsychotics. ${ }^{23}$

Length of stay, hospital charges, 30-day readmissions to UCH (calculated from date of discharge), and discharge location were determined from administrative data. 


\section{Obtain name and number of PCP and proxy decision maker, Query patient's COR status}

2. Vulnerable Elders Survey (VES-13) J Am Geriatr Soc 2001;49:1691-99.

a) Age: $65-74$ (0 points); $75-84$ ( 1 point); $>85$ ( 3 points)

b) Compared to other people your age, how would you describe your health?

- Excellent or Good (0 points); Fair or Poor (1 point)

c) On a typical day, are any of these activities very difficult or impossible to do?

- Stooping, crouching, or kneeling?

- Lifting or carrying objects as heavy as 10 pounds or a sack of potatoes?

- Reaching or extending arms above shoulder level?

- Writing or handling and grasping small objects?

- Walking a quarter of a mile (that's about 2 or 3 blocks)?

- Heavy housework such as scrubbing floors or washing windows?

One point for each YES, maximum 2 points.

d) Because of your health, is it too difficult or impossible for you to perform any of these activities without help from someone else?

- Shopping for personal items, like toiletries or medications?

- Managing money, like keeping track of expenses or paying bills?

- Walking across the room (use of cane or walker is OK)?

- Doing light housework, straightening up, washing dishes, or light cleaning?

- Bathing or showering?

$A$ YES to any of these questions is worth 4 points.

3. Mini-Cog int J Geriatri Psych 2000;15.

- Have patient repeat back 3 words: Ball, Justice, Tree

- Patient draws clock with hands at " 10 minutes past 11 o'clock"

- Ask patient to repeat the 3 words

1 point for each correct word recall.

2 points for normal clock, none for abnormal clock.

4. Falls screen $J A m$ Geritatr Soc 2001;46:664-672.

- Ask patient if they have fear of falling or have fallen in the last 6 months.

5. Depression screen Med Care 2003; 41:1284-92.

VES-13 survey score $\geq$ 4 predicts high risk of needing to go to SNF on discharge.

During the last month have you often been bothered by:

- Feeling down, depressed or hopeless or had little interest or pleasure in doing things?

Yes answer to either is a positive screen.

\section{Record use of sensory and gait aids}

- Glasses, hearing aids, dentures, cane, walker, wheelchair.

Encourage use in the hospital

7. Delirium screen (CAM tool) Am Coll Phys 1990;113:941-948

- Acute onset and fluctuating course AND inattention PLUS EITHER:

- Disorganized thinking OR altered level of consciousness

Mini-cog score of 0,1 , or 2 indicates increased risk for delirium.

A positive fall screen triggers fall precautions.

. Get Up and Go Test J Am Geriatr Soc. 1991;39:142-148.

Direct patient to do the following:

- Rise from sitting position

- Walk 10 feet

- Turn around

- Return to chair and sit down

Failing Get Up and Go triggers a PT consult. Unsteadiness triggers fall precautions.

$<20$ seconds is passing.

20-30 seconds is marginal,

$>30$ seconds is failing

FIG. 1. Hospitalist-ACE service brief geriatric screen. Abbreviation: ACE, Acute Care for the Elderly; CAM, Confusion Assessment Method; COR status, code status; PCP, Primary Care Physician; PT, physical therapist; VES-13, Vulnerable Elders Survey.

\section{Additional Descriptive Variables}

Name, medical record number, gender, date of birth, date of admission and discharge, and primary diagnosis were obtained from the medical record. The Case
Mix Index for each group of patients was determined from the average Medicare Severity-adjusted Diagnosis Related Group (MS-DRG) weight obtained from administrative data. 


\begin{tabular}{|c|c|c|c|}
\hline Measure & Criterion & Source & Content Examples \\
\hline \multirow[t]{5}{*}{$\begin{array}{l}\text { Recognition of abnormal } \\
\text { functional status* }\end{array}$} & 1) Detection & $\begin{array}{l}\text { MD's documentation of history } \\
O R\end{array}$ & Presentation with change in function (new gait instability); use of gait aides (wheelchair) \\
\hline & & $\begin{array}{l}\text { MD's documentation of physical } \\
\text { exam }\end{array}$ & $\begin{array}{l}\text { Observation of abnormal gait (eg, unsteady, wide-based, shuffling) and/or balance } \\
\text { Abnormal Get Up and Go test }\end{array}$ \\
\hline & AND & & \\
\hline & 2) Treatment & $\begin{array}{l}\text { MD's order } \\
\text { OR }\end{array}$ & PT/OT consult; home safety evaluation \\
\hline & & $\begin{array}{l}\text { MD's documentation } \\
\text { assessment/plan }\end{array}$ & Inclusion of functional status (rehabilitation, PT/OT needs) on the MD's problem list \\
\hline $\begin{array}{l}\text { Recognition of abnormal } \\
\text { cognitive status }\end{array}$ & Any of the following: & & \\
\hline \multirow[t]{5}{*}{ Delirium $^{\dagger}$} & 1) Detection & $\begin{array}{l}\text { MD's history } \\
\text { OR }\end{array}$ & Presentation of confusion or altered mental status \\
\hline & & MD's physical exam & Abnormal confusion assessment method \\
\hline & AND & & \\
\hline & 2) Treatment & $\begin{array}{l}\text { MD's order } \\
\text { OR }\end{array}$ & Sitter, reorienting communication, new halperidol order \\
\hline & & $\begin{array}{l}\text { MD's documentation of } \\
\text { assessmentplan }\end{array}$ & Inclusion of delirium on the problem list \\
\hline \multicolumn{4}{|l|}{ OR } \\
\hline \multirow[t]{5}{*}{ Dementia $^{\ddagger}$} & 1) Detection & $\begin{array}{l}\text { MD's history } \\
\text { OR }\end{array}$ & $\begin{array}{l}\text { Dementia in medical history } \\
\text { OR }\end{array}$ \\
\hline & & MD's physical exam & Abnormal Folstein Mini-Mental Status Exam or Mini-Cog \\
\hline & AND & & \\
\hline & 2) Treatment & $\begin{array}{l}\text { MD's order } \\
\text { OR }\end{array}$ & $\begin{array}{l}\text { Cholinesterase inhibitor ordered } \\
\text { OR }\end{array}$ \\
\hline & & $\begin{array}{l}\text { MD's documentation of } \\
\text { assessmentplan }\end{array}$ & Inclusion of dementia on the problem list \\
\hline \multicolumn{4}{|c|}{ 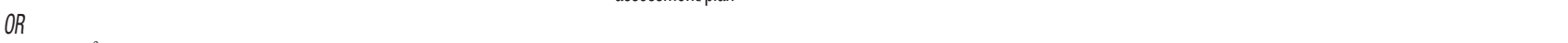 } \\
\hline \multirow[t]{5}{*}{ Depression $^{\S}$} & 1) Detection & $\begin{array}{l}\text { MD's history } \\
\text { OR }\end{array}$ & $\begin{array}{l}\text { Depression in medical history } \\
\text { OR }\end{array}$ \\
\hline & & MD's physical exam & Positive depression screen \\
\hline & AND & & \\
\hline & 2) Treatment & $\begin{array}{l}\text { MD's order } \\
\text { OR }\end{array}$ & New antidepressant order \\
\hline & & $\begin{array}{l}\text { MD's documentation of } \\
\text { assessment/plan }\end{array}$ & Inclusion of depression on the problem list \\
\hline
\end{tabular}

Abbreviation: MD, medical doctor; delta MS, delta mental status; PT/OT, physical therapist/occupational therapist. *Abnormal functional status was dependence in any one of the following physical functions: ambulation, dressing, toileting, feeding, continence, transferring, housekeeping, food shopping, transportation, laundry, or meal preparation. ${ }^{\dagger}$ Synonyms of delirium included: acute confusional state, confusion, sundowning, waxing and waning mental status; "alert and oriented time 0,1 , or 2," "delta MS," or "change in mental status" was only considered indicative of delirium if a second sign or symptom consistent with delirium was documented. "Synonyms of dementia included: memory loss, progressive/worsening forgetfulness, Alzheimer's disease, senility, senile, cognitive impairment. ${ }^{\S}$ Synonyms of depression included: depressed mood/affect, feeling sad/blue/hopeless/down in the dumps or other synonyms for sad over a period of time.

\section{Data Collection}

A two-step, retrospective chart abstraction was employed. A professional research assistant (P.R.A.) hand-abstracted process measures from the paper medical chart onto a data collection form designed for this study. A physician investigator performed a secondary review (H.L.W.). Discrepancies were resolved by the physician reviewer.

\section{Data Analysis}

Descriptive statistics were performed on intervention and control subjects. Means and standard deviations (age) or frequencies (gender, primary diagnoses) were calculated as appropriate. $T$ tests were used for continuous variables, chi-square tests for gender, and the Wilcoxon rank sum test for categorical variables.
Outcomes were reported as means and standard deviations for continuous variables (length of stay and charges) and frequencies for categorical variables (all other outcomes). $T$ tests were used for continuous variables, Fisher's exact test for restraint use, and chisquare tests were used for categorical variable to compare the impact of the intervention between intervention and control patients. For falls, confidence intervals were calculated for the incidence rate differences based on Poisson approximations.

\section{Sample Size Considerations}

An a priori sample size calculation was performed. A 2001 study showed that functional status is poorly documented in at least $60 \%$ of hospital charts of elderly patients. ${ }^{5}$ Given an estimated sample size of 120 per group and a power of $80 \%$, this study was 


\begin{tabular}{|c|c|c|c|}
\hline Characteristic & $\begin{array}{l}\text { Hospitalist-ACE } \\
\mathrm{N}=122\end{array}$ & $\begin{array}{l}\text { Usual Care } \\
\mathrm{N}=95\end{array}$ & $P$ Value \\
\hline Age (years), mean (SD) & $80.5(6.5)$ & $80.7(7.0)$ & 0.86 \\
\hline Gender (\% female) & 52.5 & 59 & 0.34 \\
\hline Case Mix Index (mean MS-DRG weight [SD]) & $1.15(0.43)$ & $1.05(0.31)$ & 0.06 \\
\hline Primary ICD-9 diagnosis (\%) & & & 0.59 \\
\hline Pulmonary & 27.9 & 28.4 & \\
\hline General medicine & 15.6 & 11.6 & \\
\hline Surgery & 13.9 & 11.6 & \\
\hline Cardiology & 9.8 & 6.3 & \\
\hline Nephrology & 8.2 & 7.4 & \\
\hline
\end{tabular}

Abbreviations: ACE, Acute Care for the Elderly; ICD-9, International Classification of Diseases, Ninth Revision; MS-DRG, Medicare Severity-adjusted Diagnosis Related Group; SD, standard deviation.

\begin{tabular}{llll}
\hline \multicolumn{2}{l}{ TABLE 3. Processes of Care } & & \\
\hline & $\begin{array}{l}\text { Percent of } \\
\text { Hospitalist-ACE } \\
\text { Patients }\end{array}$ & $\begin{array}{l}\text { Percent of } \\
\text { Usual Care } \\
\text { Patients }\end{array}$ & \\
Measure & $\mathrm{N}=122$ & $\mathrm{~N}=95$ & $P$ Value \\
\hline Recognition and treatment of abnormal functional status & 68.9 & 35.8 & $<0.0001$ \\
Recognition and treatment of abnormal cognitive status* & 55.7 & 40.0 & 0.02 \\
Recognition and treatment of delirium & 27.1 & 17.0 & 0.08 \\
Documentation of resuscitation preferences & 95.1 & 91.6 & 0.3 \\
Do Not Attempt Resuscitation orders & 39.3 & 26.3 & 0.04 \\
Use of sleep medications & 28.1 & 27.4 & 0.91 \\
Use of physical restraints & 2.5 & 0 & 0.26 \\
\hline Abbreviation: ACE, Acute Care for the Elderly. ${ }^{*}$ Abnormal cognitive status includes delirium, dementia, and depression. & \\
\hline
\end{tabular}

powered to be able to detect an absolute difference in the documentation of functional status of as little as $18 \%$.

\section{RESULTS}

Two hundred seventeen patients met the study entry criteria (Table 2): 122 were admitted to the Hospitalist-ACE service, and 95 were admitted to usual care on the general medical services. The average age of the study patients was 80.5 years, $55.3 \%$ were female. Twenty-eight percent of subjects were admitted for pulmonary diagnoses. The two groups of patients were similar with respect to age, gender, and distribution of primary diagnoses. The Hospitalist-ACE patients had a mean MS-DRG weight of 1.15 , which was slightly higher than that of usual care patients at $1.05(P=0.06)$. Typically, $70 \%$ of Hospitalist-ACE patients are admitted to the designated ACE medical unit (12 West).

\section{Processes of Care}

Processes of care for older patients are displayed in Table 3. Patients on the Hospitalist-ACE service had recognition and treatment of abnormal functional status at a rate that was nearly double that of patients on the usual care services $(68.9 \%$ vs $35.8 \%, P<0.0001)$. In addition, patients on the Hospitalist-ACE service were significantly more likely to have had recognition and treatment of any abnormal cognitive status $(55.7 \%$ vs $40.0 \%, P=0.02)$. When delirium was evaluated alone, the Hospitalist-ACE patients were also more likely to have had recognition and treatment of delirium $(27.1 \%$ vs $17.0 \%, P=0.08$ ), although this finding did not reach statistical significance.

While patients on the Hospitalist-ACE and usual care services had similar percentages of documentation of resuscitation preferences $(95.1 \%$ vs $91.6 \%, P$ $=0.3$ ), the percentage of Hospitalist-ACE patients who had Do Not Attempt Resuscitation (DNAR) orders was significantly greater than that of the usual care patients $(39.3 \%$ vs $26.3 \%, P=0.04)$.

There were no differences in the use of physical restraints or sleep medications for Hospitalist-ACE patients as compared to usual care patients, although the types of sleep mediations used on each service were markedly different: trazadone was employed as the first-line sleep agent on the Hospitalist-ACE service $(77.7 \%)$, and non-benzodiazepine hypnotics (primarily zolpidem) were employed most commonly on the usual care services $(35 \%)$. There were no differences noted in the percentage of patients with benzodiazepines prescribed as sleep aids.

\section{Outcomes}

Resource utilization outcomes are reported in Table 4. Of note, there were no significant differences between 
TABLE 4. Outcomes

\begin{tabular}{llll}
\hline Measure & Hospitalist-ACE & Usual Care & \\
& $\mathrm{N}=122$ & $\mathrm{~N}=95$ & $P$ Value \\
\hline Length of stay in days (mean [SD]) & $3.4(2.7)$ & $3.1(2.7)$ & 0.52 \\
Charges in dollars (mean [SD]) & $24,617(15,828)$ & $21,488(13,407)$ & 0.12 \\
30-Day readmissions to UCH (\%) & 12.3 & 9.5 & 0.51 \\
Discharges to home (\%) & $68.8^{*}$ & 67.4 & 0.84 \\
Discharges to home with services $(\%)^{\dagger}$ & $14 \%^{*}$ & $7.4 \%$ & 0.12 \\
\hline
\end{tabular}

Abbreviations: ACE, Acute Care for the Elderly; SD, standard deviation; UCH, University of Colorado Hospital. ${ }^{*} n=121$ (one ACE patient expired in the hospital and was excluded from this analysis). ${ }^{\dagger}$ Includes home health and home hospice.

Hospitalist-ACE discharges and usual care discharges in mean length of stay $(3.4 \pm 2.7$ days vs $3.1 \pm 2.7$ days, $P=0.52)$, mean charges $(\$ 24,617 \pm 15,828$ vs $\$ 21,488 \pm 13,407, P=0.12$ ), or 30 -day readmissions to $\mathrm{UCH}(12.3 \%$ vs $9.5 \%, P=0.51)$. Hospitalist-ACE discharges and usual care patients were equally likely to be discharged to home $(68.6 \%$ vs $67.4 \%, P=$ 0.84 ), with a similar proportion of Hospitalist-ACE discharges receiving home health care or home hospice services $(14.1 \%$ vs $7.4 \%, P=12)$.

In addition, the fall rate for Hospitalist-ACE patients was not significantly different from the fall rate for usual care patients $(4.8$ falls/1000 patient days vs 6.7 falls/1000 patient days, $95 \%$ confidence interval $-9.6-13.3)$.

\section{DISCUSSION}

We report the implementation and evaluation of a medical service tailored to the care of the acutely ill older patient that draws from elements of the hospitalist model and the ACE unit model. ${ }^{7,14,24}$ For this Hospitalist-ACE service, we developed a specialized hospitalist workforce, assembled a brief geriatric assessment tailored to the inpatient setting, instituted an interdisciplinary rounding model, and created a novel inpatient geriatrics curriculum.

During the study period, we improved performance of important processes of care for hospitalized elders, including recognition of abnormal cognitive and functional status; maintained comparable resource use; and implemented a novel, inpatient-focused geriatric medicine educational experience. We were unable to demonstrate an impact on key clinical outcomes such as falls, physical restraint use, and readmissions. Nonetheless, there is evidence that the performance of selected processes of care is associated with improved three-year survival status in the community-dwelling vulnerable older patient, and may also be associated with a mortality benefit in the hospitalized vulnerable older patient. ${ }^{25,26}$ Therefore, methods to improve the performance of these processes of care may be of clinical importance.

The finding of increased use of DNAR orders in the face of equivalent documentation of code status is of interest and generates hypotheses for further study. It is possible that the educational experience and use of geriatric assessment provides a more complete context for the code status discussion (one that incorporates the patient's social, physical, and cognitive function). However, we do not know if the patients on the ACE service had improved concordance between their code status and their goals of care.

We believe that there was no difference in key clinical outcomes between Hospitalist-ACE and control patients because the population in this study was relatively low acuity and, therefore, the occurrence of falls and the use of physical restraints were quite low in the study population. In particular, the readmission rate was much lower than is typical for the Medicare population at our hospital, making it challenging to draw conclusions about the impact of the intervention on readmissions, however, we cannot rule out the possibility that our early discharge planning did not address the determinants of readmission for this population.

The ACE unit paradigm - characterized by 1) closed, modified hospital units; 2) staffing by geriatricians and nurses with geriatrics training; 3 ) employing geriatric nursing care protocols-requires significant resources and is not feasible for all settings. ${ }^{6}$ There is a need for alternative models of comprehensive care for hospitalized elders that require fewer resources in the form of dedicated units and specialist personnel, and can be more responsive to institutional needs. For example, in a 2005 report, one institution reported the creation of a geriatric medicine service that utilized a geriatrician and hospitalist co-attending model. ${ }^{14}$ More recently, a large geriatrics program replaced its inpatient geriatrics unit with a mobile inpatient geriatrics service staffed by an attending geriatrician-hospitalist, a geriatrics fellow, and a nurse practitioner. ${ }^{27}$ While these innovative models have eliminated the dedicated unit, they rely on board certified geriatricians, a group in short supply nationally. ${ }^{28}$ Hospitalists are a rapidly growing provider group that, with appropriate training and building on the work of geriatricians, is poised to provide leadership in acute geriatric care. ${ }^{29,30}$ 
In contrast to the comprehensive inpatient geriatric care models described above, the Hospitalist-ACE service uses a specialized hospitalist workforce and is not dependent on continuous staffing by geriatricians. Although geographic concentration is important for the success of interdisciplinary rounds, the Hospitalist-ACE service does not require a closed or modified unit. The nursing staff caring for Hospitalist-ACE patients have generalist nursing training and, at the time of the study, did not utilize geriatric-care protocols. Our results need to be interpreted in the light of these differences from the ACE unit model which is a significantly more intensive intervention than the Hospitalist-ACE service. In addition, the current practice environment is quite different from the mid-1990s when ACE units were developed and studied. Development and maintenance of models of comprehensive inpatient geriatric care require demonstration of both value as well as return on investment. The alignment of financial and regulatory incentives for programs that provide comprehensive care to complex patients, such as those anticipated by the Affordable Care Act, may encourage the growth of such models.

These data represent findings from a six-month evaluation of a novel inpatient service in the middle of its first year. There are several limitations related to our study design. First, the results of this small study at a single academic medical center may be of limited generalizability to other settings. Second, the program was evaluated only three months after its inception; we did not capture further improvements in methods, training, and outcomes expected as the program matured. Third, most of the Hospitalist-ACE service attendings and residents rotate on the $\mathrm{UCH}$ general medical services throughout the year. Consequently, we were unable to eliminate the possibility of contamination of the control group, and we were unable to blind the physicians to the study. Fourth, the study population had a relatively low severity of illness-the average MS-DRG weight was near 1 -and low rates of important adverse events such falls and restraint use. This may have occurred because we excluded patients transferred from the ICUs and other services. It is possible that the Hospitalist-ACE intervention might have demonstrated a larger benefit in a sicker population that would have presented greater opportunities for reductions in length of stay, costs, and adverse events. Fifth, given the retrospective nature of the data collection, we were not able to prospectively assess the incidence of important geriatric outcomes such as delirium and functional decline, nor can we make conclusions about changes in function during the hospitalization.

While the outcome measures we used are conceptually similar to several measures developed by RAND's Assessing Care of Vulnerable Elders (ACOVE) project, this study did not explicitly rely on those constructs. ${ }^{31}$ To do so would have required prospective screening by clinical staff independent from the care team for vulnerability that was beyond the scope of this project. In addition, the ACOVE measures of interest for functional and cognitive decline are limited to documentation of cognitive or functional assessments in the medical record. The ACE service's adoption of a brief standardized geriatric assessment was almost certain to meet that documentation requirement. While documentation is important, it is not clear that documentation, in and of itself, improves outcomes. Therefore, we expanded upon the ACOVE constructs to include the need for the additional evidence of a treatment plan when abnormal physical or cognitive function was documented. These constructs are important process of care for vulnerable elders. While we demonstrated improvements in several of these important processes of care for elderly patients, we are unable to draw conclusions about the impact of these differences in care on important clinical outcomes such as development of delirium, long-term institutionalization, or mortality.

\section{CONCLUSIONS}

The risks of hospitalization for older persons are numerous, and present challenges and opportunities for inpatient physicians. As the hospitalized population agesmirroring national demographic trends and trends in use of acute care hospitals-the challenge of avoiding harm in the older hospitalized patient will intensify. Innovations in care to improve the experience and outcomes of hospitalization for older patients are needed in the face of limited geriatrics-trained workforce and few discretionary funds for unit redesign. The Hospitalist-ACE service is a promising strategy for hospitalist programs with sufficient numbers of older patients and hospitalists with interest in improving clinical care for older adults. It provides a model for hospitalists to employ geriatrics principles targeted at reducing harm to their most vulnerable patients. Hospitalist-run geriatric care models offer great promise for improving the care of acutely ill elderly patients. Future investigation should focus on demonstrating the impact of such care on important clinical outcomes between admission and discharge; on model refinement and adaptation, such as determining what components of comprehensive geriatric care are essential to success; and on how complementary interventions, such as the use of templated orders for the hospitalized elderly, impact outcomes. Additional research is needed, with a focus on demonstrating value with regard to an array of outcomes including cost, readmissions, and preventable harms of care.

\section{Acknowledgements}

Jean Kutner, MD, MSPH; Daniel Sandy, MPH; Shelly Limon, RN; nurses of 12 West; the UCH staff on the interdisciplinary team; and ACE patients and their families.

Disclosure: This work was funded by a University of Colorado Hospital Quality Improvement Small Grant. Dr. Wald was funded by a Hartford/ 
Jahnigen Center of Excellence in Aging Junior Faculty Award from 2006 to 2008, and is currently in receipt of a Paul B. Beeson Career Development Award in Aging from the National Institutes on Aging, the John A. Hartford Foundation, the Atlantic Philanthropies, and the Starr Foundation. Dr. Cumbler has received a speaker's honorarium from SCAN Health. Drs. Glasheen, Guerrasio, and Youngwerth have no potential financial conflicts of interest to disclose.

\section{References}

1. Sager MA, Franke T, Inouye SK, et al. Functional outcomes of acute medical illness and hospitalization in older persons. Arch Intern Med. 1996;156:645-652.

2. Inouye SK, Schlesinger MJ, Lyndon TJ. Delirium: a symptom of how hospital care is failing older persons and a window to improve quality of hospital care. Am I Med. 1999;106:565-573.

3. Arora VM, Johnson M, Olson J, et al. Using assessing care of vulnerable elders quality indicators to measure quality of hospital care for vulnerable elders. J Am Geriatr Soc. 2007;55(11):1705-1711.

4. Boustani M, Baker MS, Campbell N, et al. Impact and recognition of cognitive impairment among hospitalized elders. J Hosp Med. 2010; 5:69-75.

5. Bogardus ST Jr, Towle V, Williams CS, Desai MM, Inouye SK. What does the medical record reveal about functional status? A comparison of medical record and interview data. J Gen Intern Med. 2001; 16(11):728-736

6. Boult C, Green AF, Boult LB, Pacala JT, Snyder C, Leff B. Successful models of comprehensive care for older adults with chronic conditions: evidence for the Institute of Medicine's "Retooling for an Aging America” report. I Am Geriatr Soc. 2009;57(12):2328-2337.

7. Landefeld CS, Palmer RM, Kresevic DM, Fortinski RH, Kowal J. A randomized trial of care in a hospital medical unit especially designed to improve the functional outcomes of acutely ill older patients. $N$ Engl J Med. 1995;332:1338-1344.

8. Counsell SA, Holder CM, Liebenauer LL, et al. Effects of a multicomponent intervention on functional outcomes and process of care in hospitalized older adults: a randomized controlled trial of Acute Care for Elders (ACE) in a community hospital. J Am Geriatr Soc. 2000;48:1572-1581.

9. Van Craen K, Braes T, Wellens N, et al. The effectiveness of inpatient geriatric evaluation and management units: a systematic review and meta-analysis. J Am Geriatr Soc. 2010;58:83-92.

10. Baztan JJ, Suarez-Garcia FM, Lopez-Arrieta J, Rodriguez-Manas L, Rodriguez-Artalejo F. Effectiveness of acute geriatric units on functional decline, living at home, and case fatality among older patients admitted to hospital for acute medical disorders: meta-analysis. $B M J$. 2009;338:b50.

11. Allen CM, Becker PM, McVey LJ, et al. A randomized, controlled clinical trial of a geriatrics consultation team: compliance with recommendations. JAMA. 1986;255:2617-2621.

12. Inouye SK, Bogardus ST J, Charpentier PA, et al. A multicomponent intervention to prevent delirium in hospitalized older patients. $N$ Engl J Med. 1999;340:669-676.

13. Jayadevappa R, Bloom BS, Raziano DB, Lavizzo-Mourey R. Dissemination and characteristics of Acute Care of Elders (ACE) units in the United States. Int J Technol Assess Health Care. 2003;19:220-227.
14. Wald H, Huddleston J, Kramer A. Is there a geriatrician in the house? Geriatric care approaches in hospitalist programs. J Hosp Med. 2006; 1:29-35.

15. Borson S, Scanlon J, Brush M, Vitaliano P, Dokmak A. The MiniCog: a cognitive "vital signs" measure for dementia screening in multi-lingual elderly. Int J Geriatr Psychiatry. 2000;15(11): 1021-1027.

16. Kroenke K, Spitzer RL, Williams JB. The Patient Health Questionnaire-2: validity of a two-item depression screener. Med Care. 2003; 41:1284-1292.

17. Inouye S, VanDyck C, Alessi C, Balkin S, Siegal A, Horwitz R. Clarifying confusion: the Confusion Assessment Method. Ann Intern Med. 1990;113(12):941-948.

18. Saliba D, Elliot M, Rubenstein LZ, et al. The Vulnerable Elders Survey: a tool for identifying vulnerable older people in the community. $J$ Am Geriatr Soc. 2001;49:1691-1699.

19. Podsiadlo D, Richardson S. The timed "Up and Go": a test of basic functional mobility for frail elderly persons. J Am Geriatr Soc. 1991; 39:142-148.

20. American Geriatrics Society, British Geriatrics Society, and American Academy of Orthopedic Surgeons Panel on Falls Prevention. Guideline for the prevention of falls in older persons. J Am Geriatr Soc. 2001;49:664-672.

21. Cumbler E. Falls for the inpatient physician. Translating knowledge into action. The Portal of Online Geriatric Education (POGOe). 619-2008. Available at: http://www.pogoe.org/productid/20212.

22. Guerrasio J, Cumbler E, Youngwerth J, Wald H. Incontinence and urinary catheters for the inpatient physician. The Portal of Online Geriatric Education (POGOe). 11-27-0008. Available at: http:// www.pogoe.org/productid/20296.

23. Cumbler E, Guerrasio J, Kim J, Glasheen JJ. Use of medications for insomnia in the hospitalized geriatric population. J Am Geriatr Soc. 2008;56(3):579-581.

24. Lindenauer PK, Pantilat SZ, Katz PP, Wachter RM. Hospitalists and the practice of inpatient medicine: results of a survey of the National Association of Inpatient Physicians. Ann Intern Med. 1999;130(4 pt 2):343-349.

25. Higashi T, Shekelle P, Adams J, et al. Quality of care associated with survival in vulnerable older patients. Ann Intern Med. 2005;143: 274-281.

26. Fish M, Arora V, Basu A, et al. Higher quality of care for hosptialized frail older adults is associated with improved survival one year after discharge. J Hosp Med. 2009;4(S1):24.

27. Farber J, Korc B, Du Q, Siu A. Operational and quality outcomes of a novel mobile acute care for the elderly service. J Am Geriatr Soc. 2009;57:S1.

28. Institute of Medicine (IOM). Retooling for an Aging America: Building the Health Care Workforce. Washington, DC: The National Academies Press; 2008.

29. Cumbler E, Glasheen JJ, Wald HL. Alternative solutions to the geriatric workforce deficit. Am J Med. 2008;121:e23.

30. Glasheen JJ, Siegal E, Epstein KR, Kutner J, Prochazka AV. Fulfilling the promise of hospital medicine: tailoring internal medicine training to address hospitalists' needs. J Gen Intern Med. 2008;23(7): 1110-1115.

31. Wenger NS, Shekelle PG. Assessing care of vulnerable elders: ACOVE project overview. Ann Intern Med. 2001;135(8 pt 2):642-646. 